www.nature.com/pj

\title{
Effect of the molecular structure of monocyclic aromatic polymer on the application properties of concrete
}

\author{
Hui Zhao, Ming Deng and Tang Mingshu
}

New water-soluble monocyclic aromatic (MA) polymers, including sulfonated phenol-formaldehyde polymer (SPF), aminosulfonate-phenol-formaldehyde polymer (AS) and aminosulfonate-phenol-salicylic acid-formaldehyde polymer (AH), were synthesized. The molecular structure of the MA polymers was characterized by gel permeation chromatography and infrared spectroscopy. The application properties of the MA polymers in concrete were also evaluated. The test results showed that the MA polymers have approximately the same molecular weight. The molecular structure of the SPF polymer was observed to have more $-\mathrm{SO}_{3}$ and fewer $-\mathrm{OH}$ groups than the other polymers and exhibits a high percentage of water-reduction percentage, high slump loss and poor workability-preservation properties. The molecular structure of the $\mathrm{AS}$ and $\mathrm{AH}$ polymers features $-\mathrm{SO}_{3}$ and $\mathrm{COOH}$ as dispersion groups, and $-\mathrm{OH}$ and $-\mathrm{NH}_{2}$ as fluidity preservation groups, such that they exhibit better water-reducing capacity, workability-preservation properties, retardation of the setting time for cement paste and higher compressive strengths for concrete than the SPF polymer at the same curing time and dosage.

Polymer Journal (2011) 43, 859-865; doi:10.1038/pj.2011.72; published online 27 July 2011

Keywords: application properties; MA polymer; molecule structure

\section{INTRODUCTION}

High-performance concrete (HPC) is a novel construction material that exhibits higher workability, greater mechanical properties and better durability than conventional concrete. ${ }^{1,2}$ Superplasticizer is an essential component in HPC. . $^{3,4}$

Superplasticizers can be classified into three groups according to their chemical structure: ${ }^{5,6}$ naphthalene formaldehyde sulfonated condensates, melamine formaldehyde sulfonated condensates and polycarboxylate polymers with long comb-type side chains. ${ }^{7-9}$

Over the last two decades, new water-soluble monocyclic aromatic (MA) polymers have been developed: sulfonated phenol-formaldehyde polymer (SPF), aminosulfonate-phenol-formaldehyde polymer (AS) and aminosulfonate-phenol-salicylic acid-formaldehyde polymer $(\mathrm{AH})$. The main chains of MA polymers are bound by alternating phenyl and methylene groups that possess $-\mathrm{OH},-\mathrm{COOH},-\mathrm{NH}_{2}$ and $-\mathrm{SO}_{3}$ hydrophilic groups. Researchers have recently studied synthetic methods for producing MA polymers as well as the application properties of MA polymers in concrete. ${ }^{10-14}$ However, the effect of functional groups bonded to the molecular backbone of MA polymers on the application properties of concrete has not been a subject of research.

In this study, three types of MA polymer with different functional groups were synthesized. The molecular structure of the MA polymers was characterized by gel permeation chromatography and infrared spectroscopy. The effect of the functional groups bonded to the molecular structure of the MA polymers on water reduction, workability preservation of concrete and setting time of cement paste was studied. The relationship between the setting time and slump loss in concrete containing MA polymers with different functional groups, the compressive strength of concrete containing MA polymers with different functional groups at difference dosages and the water/cement (W/C) ratios were also investigated.

\section{EXPERIMENTAL PROCEDURE}

Synthesis of MA polymer

Synthesis of SPF polymer. Sodium bisulfite (S) and phenol (P) were dissolved in water in a reaction vessel equipped with a stirrer and reflex condenser. The temperature of the solution was heated to $80^{\circ} \mathrm{C}$ before the solution became clear; as soon as the solution became clear, the $\mathrm{pH}$ value of the solution was adjusted to $\mathrm{pH} 10-11$ with a $40 \%$ sodium hydroxide solution. A $37 \%$ concentration formaldehyde (F) solution was fed into the reactor through a dropping funnel for 10-20 min, and the temperature of the solution was kept at $80^{\circ} \mathrm{C}$. The temperature of the solution was raised to $85-90^{\circ} \mathrm{C}$, and the reaction was allowed to continue for $4 \mathrm{~h}$.

Synthesis of AS polymer. Sodium sulfanilate and phenol (P) were dissolved in water in a reaction vessel equipped with a stirrer and reflex condenser. The temperature of the solution was raised to $80^{\circ} \mathrm{C}$ before the solution became clear; as soon as the solution became clear, the $\mathrm{pH}$ value of the solution was adjusted to $\mathrm{pH} 10-11$ with a $40 \%$ sodium hydroxide solution. The temperature 
was kept at $80^{\circ} \mathrm{C}$, and a $37 \%$ concentration formaldehyde (F) solution was fed into the reactor through a dropping funnel for 10-20 $\mathrm{min}$. Then, the temperature of the solution was raised to $85-90^{\circ} \mathrm{C}$, and the reaction was allowed to continue for $4 \mathrm{~h}$.

Synthesis of AH polymer. Sodium sulfanilate, salicylic acid (C) and phenol (P) were dissolved in water in a reaction vessel equipped with a stirrer and reflex condenser. The temperature of the solution was raised to $80^{\circ} \mathrm{C}$ before the solution became clear; as soon as the solution became clear, the $\mathrm{pH}$ value of the solution was adjusted to $\mathrm{pH} 10.45$ with a $40 \%$ sodium hydroxide solution. The temperature was kept at $80^{\circ} \mathrm{C}$, and a $37 \%$ concentration formaldehyde (F) solution was fed into the reactor through a dropping funnel for 10-20 min. Then the temperature of the solution was raised to $85-90^{\circ} \mathrm{C}$, and the reaction was allowed to continue for $4 \mathrm{~h}$

\section{The molecule structure characterization of MA polymer}

Gel permeation chromatographymeasurements. The molecular weight (MW) and MW distribution of the MA polymers were determined using a Waters 1515 (USA) gel permeation chromatograph instrument equipped with Ultrahydrogel 120 and 250 columns, $0.10 \mathrm{moll}^{-1}$ of sodium chloride solution as a mobile phase at a flow rate of $0.60 \mathrm{ml} \mathrm{min}^{-1}$ and sodium polystyrene sulfonate as a standard.

Fourier transform infrared analysis. The dried MA polymer was further ground into powder before the determination of the MA polymer molecular structure and other procedures. Then, the proper amount of MA polymer powder samples was mixed with predried $\mathrm{KBr}$ and pressed into disks. Transmission infrared spectra of the disk samples was recorded using a Genesis FT-IR instrument (NEXUS 670 FT-IRESP, Nicolet, USA) in the region from 400 to $4000 \mathrm{~cm}^{-1}$.

\section{The application properties test of concrete}

Materials. Cement: Ordinary Portland cement (CEM1) according to BS EN 197(see ref. 15) was used in this study. The chemical compositions and physical properties of cement are presented in Tables 1 and 2.

Polymer: The chemical structure of the MA polymers is shown in Figure 1; the properties of the MA polymers are shown in Table 3.

Aggregates: Natural crushed stone with particles sizes between 5 and $20 \mathrm{~mm}$ with continuous gradation was used in this study. The fine aggregates used were natural river sand from China. The physical properties and the particle size distribution of fine and coarse aggregates are presented in Tables 4 and 5.

Mixture proportions. Concrete containing the MA polymer was prepared. The mixed proportion of concrete was as follows: cement/sand/gravel=1:2.16:3.54, cement $=330 \mathrm{~kg} \mathrm{~m}^{-3}$, initial slump $=8.0-9.0 \mathrm{~cm}$ and air content $<4.5 \%$. The mixed proportions of concrete with different dosages of MA polymer are shown in Table 6.

Preparation of samples. The components of concrete were batched by weight. Cement was premixed with coarse and fine aggregates for $1 \mathrm{~min}$. Then, the mixing water with the dissolved MA polymer was added and mixed for $3 \mathrm{~min}$.
Finally, the concrete mixture was mixed for an additional $2 \mathrm{~min}$, resulting in a total mixing period of $6 \mathrm{~min}$. The samples were compacted using a laboratory vibrating table for 2-3 min at a frequency of $50 \mathrm{~Hz}$ and a vibration amplitude of $0.5 \mathrm{~mm}$; the samples were cured at $20^{\circ} \mathrm{C}$ in molds covered by a polyethylene film to prevent moisture loss according to GOST10180. ${ }^{16}$ The samples were removed from the molds after $24 \mathrm{~h}$ and cured under a humidified atmosphere at a temperature of $20^{\circ} \mathrm{C}$ with a relative humidity of $90 \pm 5 \%$, until testing.

Experimental methods. Workability test: The workability of concrete was indicated by the initial slump value of the material measured by a slump test according to BS EN 12350 Part 2 (BS EN.2000). ${ }^{17}$ The workability change of concrete with different dosages of MA polymer was measured by the slump variations of concrete during the elapsed time. Before the test, concrete with

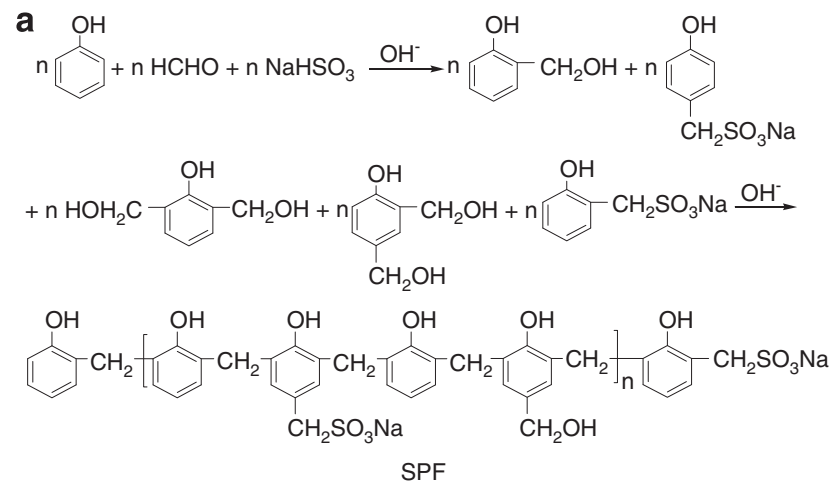

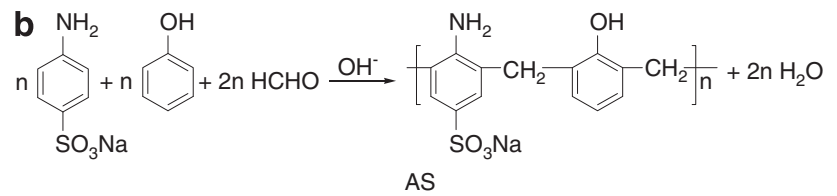<smiles></smiles>

Figure 1 Chemical structure of monocyclic aromatic (MA) polymer. (a) Sulfonated phenol-formaldehyde polymer (SPF). (b) Aminosulfonatephenol-formaldehyde polymer (AS). (c) Aminosulfonate-phenol-salicylic acidformaldehyde polymer (AH).

Table 1 Chemical compositions of cement (\%)

\begin{tabular}{|c|c|c|c|c|c|c|c|c|c|c|c|c|c|}
\hline $\mathrm{SiO}_{2}$ & $\mathrm{Al}_{2} \mathrm{O}_{3}$ & $\mathrm{CaO}$ & $\mathrm{Fe}_{2} \mathrm{O}_{3}$ & $\mathrm{MgO}$ & $\mathrm{SO}_{3}$ & $\mathrm{~K}_{2} \mathrm{O}$ & $\mathrm{Na}_{2} \mathrm{O}$ & $\mathrm{TiO}_{2}$ & $C_{3} S$ & $C_{2} S$ & $C_{3} A$ & $C_{4} A F$ & Loss \\
\hline
\end{tabular}

Table 2 Physical properties of cement

\begin{tabular}{|c|c|c|c|c|c|c|}
\hline \multirow[b]{2}{*}{ Sample } & \multicolumn{2}{|c|}{ Setting time (min) } & \multicolumn{2}{|c|}{ Flexural strength (MPa) } & \multicolumn{2}{|c|}{ Compressive strength ( $\mathrm{MPa}$ ) } \\
\hline & Intial & Final & 3 days & 28 days & 3 days & 28 days \\
\hline Portland cement & 307 & 440 & 5.8 & 8.3 & 27.1 & 50.6 \\
\hline
\end{tabular}


Table 3 Properties of MA polymer

\begin{tabular}{lccc}
\hline Property & SPF & AS & AH \\
\hline Appearance & Red liquid & Dark brown liquid & Dark brown liquid \\
Solid content (\%) & 30 & 30 & 30 \\
$\mathrm{pH}$ & 11.1 & 11.4 & 11.6 \\
Alkali content (\%) & 4.51 & 4.76 & 4.08 \\
Sodium sulfate content (\%) & 0.88 & 0.68 & 0.54 \\
Chloride content (\%) & 0.01 & 0.01 & 0.01
\end{tabular}

Abbreviations: AH, aminosulfonate-phenol-salicylic acid-formaldehyde polymer; AS, aminosulfonate-phenol-formaldehyde polymer; MA, monocyclic aromatic; SPF, sulfonated phenol-formaldehyde polymer.

Table 4 Physical properties of fine aggregate and coarse aggregate

\begin{tabular}{lcc}
\hline Properties & Fine aggregate & Coarse aggregates \\
\hline Density-OD $\left(\mathrm{kg} \mathrm{m}^{-3}\right)$ & 2585 & 4054 \\
Density-SSD $\left(\mathrm{kg} \mathrm{m}^{-3}\right)$ & 2620 & 4112 \\
Water absorption (\%) & 0.87 & 1.49 \\
\hline
\end{tabular}

Abbreviations: OD, optical density; SSD, saturated surface dry.

Table 5 Grading of fine aggregate and coarse aggregates

\begin{tabular}{|c|c|c|}
\hline \multirow[b]{2}{*}{ Sieve size $(\mathrm{mm})$} & \multicolumn{2}{|c|}{ Cumulative pass amount (\%) } \\
\hline & Fine aggregate & Coarse aggregates \\
\hline 20 & - & 75.76 \\
\hline 15 & - & 42.3 \\
\hline 10 & - & 5.26 \\
\hline 5 & 100 & 0.6 \\
\hline 4.75 & 95.4 & - \\
\hline 2.36 & 82.8 & - \\
\hline 1.18 & 72.2 & - \\
\hline 0.6 & 52.2 & - \\
\hline 0.3 & 31.0 & - \\
\hline 0.15 & 3.2 & - \\
\hline Fineness modulus & 2.46 & - \\
\hline Apparent density $\left(\mathrm{kg} \mathrm{m}^{-3}\right)$ & - & 2760 \\
\hline Bulk density $\left(\mathrm{kg} \mathrm{m}^{-3}\right)$ & - & 1450 \\
\hline Density_OD $\left(\mathrm{kg} \mathrm{m}^{-3}\right)$ & 2580 & 2635 \\
\hline Density—SSD $\left(\mathrm{kg} \mathrm{m}^{-3}\right)$ & 2620 & 2680 \\
\hline Water absorption (\%) & 0.80 & 1.2 \\
\hline
\end{tabular}

Abbreviations: OD, optical density; SSD, saturated surface dry.

different dosages of MA polymer was mixed for 1-2 min by hand; the slump values of concrete were checked 30, 60, 90 and 120 min after the first test.

Setting times test: The setting times of the cement pastes were tested according to the European standard EN 196-3. ${ }^{18}$

Compressive strength test: Concrete samples in the form of $100 \mathrm{~mm}^{3}$ cubes were prepared. Compressive strength tests were carried out at 3, 7 and 28 days according to GOST 10180.

\section{RESULTS AND DISCUSSION}

Molecular structure characterization of synthesized MA polymer Gel permeation chromatography.

Fourier transform infrared analysis.

Molecular structure characterization of MA polymer. The molecular weight (MW) and weight distribution of MA polymers are shown in
Table 6 Mix proportions of concrete with difference dosages MA polymer

\begin{tabular}{|c|c|c|c|c|c|c|c|}
\hline \multirow[b]{3}{*}{ Sample } & \multirow[b]{3}{*}{$W / B$} & \multirow[b]{3}{*}{$\begin{array}{c}\text { Polymer } \\
\text { dosage } \\
(\%)\end{array}$} & \multicolumn{4}{|c|}{ Proportion $\left(\mathrm{kg} \mathrm{m}^{-3}\right)$} & \multirow[b]{3}{*}{$\begin{array}{l}\text { Initial } \\
\text { slump } \\
(\mathrm{cm})\end{array}$} \\
\hline & & & \multirow[b]{2}{*}{$\begin{array}{c}\text { Water } \\
(W)\end{array}$} & \multirow[b]{2}{*}{$\begin{array}{c}\text { Cement } \\
\text { (C) }\end{array}$} & \multirow{2}{*}{$\begin{array}{c}\text { Fine } \\
\text { aggregate } \\
\\
\text { River } \\
\text { sand }(R)\end{array}$} & \multirow{2}{*}{$\begin{array}{c}\text { Coarse } \\
\text { aggregate }\end{array}$} & \\
\hline & & & & & & & \\
\hline 0 & 0.61 & 0 & 201.3 & 330 & 710 & 1158 & 8.2 \\
\hline SPF & 0.55 & 0.3 & 181.5 & 330 & 710 & 1158 & 9.0 \\
\hline SPF & 0.52 & 0.4 & 171.6 & 330 & 710 & 1158 & 9.0 \\
\hline SPF & 0.49 & 0.5 & 161.7 & 330 & 710 & 1158 & 9.0 \\
\hline SPF & 0.47 & 0.6 & 155.1 & 330 & 710 & 1158 & 9.0 \\
\hline AS & 0.45 & 0.3 & 148.5 & 330 & 710 & 1158 & 8.2 \\
\hline AS & 0.44 & 0.4 & 145.2 & 330 & 710 & 1158 & 9.0 \\
\hline AS & 0.43 & 0.5 & 141.9 & 330 & 710 & 1158 & 8.2 \\
\hline AS & 0.41 & 0.6 & 135.3 & 330 & 710 & 1158 & 8.8 \\
\hline $\mathrm{AH}$ & 0.44 & 0.3 & 145.2 & 330 & 710 & 1158 & 8.5 \\
\hline $\mathrm{AH}$ & 0.42 & 0.4 & 138.6 & 330 & 710 & 1158 & 8.7 \\
\hline $\mathrm{AH}$ & 0.41 & 0.5 & 135.3 & 330 & 710 & 1158 & 8.8 \\
\hline $\mathrm{AH}$ & 0.40 & 0.6 & 132.0 & 330 & 710 & 1158 & 8.8 \\
\hline
\end{tabular}

Abbreviations: AH, aminosulfonate-phenol-salicylic acid-formaldehyde polymer; AS, aminosulfonate-phenol-formaldehyde polymer; MA, monocyclic aromatic; SPF, sulfonated phenol-formaldehyde polymer.

Table 7 Characteristic of molecular distributing on MA polymer

\begin{tabular}{lcccccc}
\hline Polymer type & $\mathrm{M}_{n}$ & $\mathrm{M}_{p}$ & $\mathrm{M}_{w}$ & $\mathrm{M}_{z}$ & $\mathrm{M}_{z+1}$ & $\begin{array}{c}\text { Polydispersity } \\
\text { index }\end{array}$ \\
\hline $\mathrm{SPF}$ & 16828 & 15827 & 18654 & 20770 & 23032 & 1.11 \\
$\mathrm{AS}$ & 22735 & 22866 & 25731 & 29115 & 32606 & 1.13 \\
$\mathrm{AH}$ & 15813 & 16887 & 23806 & 36337 & 50322 & 1.505
\end{tabular}

Abbreviations: AH, aminosulfonate-phenol-salicylic acid-formaldehyde polymer; AS, aminosulfonate-phenol-formaldehyde polymer; MA, monocyclic aromatic; SPF, sulfonated phenol-formaldehyde polymer.

Table 7, which shows that the weight-average MW and the numberaverage MW $(\mathrm{Mn})$ of the MA polymers are $1.9 \times 10^{4}-2.6 \times 10^{4} \mathrm{Da}$ and $1.58 \times 10^{4}-2.29 \times 10^{4} \mathrm{Da}$. The polydispersity $(\mathrm{MW} / \mathrm{Mn})$ of the MA polymers is about $1.1-1.505$, suggesting that the MW of the synthesized MA polymers is distributed across a narrower range in which the most probable distribution is centered around 16000-23000 Da. The MA polymers have approximately the same MW.

Although the MA polymers have approximately the same MW, they possess different application properties in concrete. To understand this difference, functional groups bonded to the MA polymer molecular structure were examined and are shown in Table 8; the molecular structure of the SPF, AS and $\mathrm{AH}$ polymers has $-\mathrm{OH}$ and $-\mathrm{SO}_{3} ;-\mathrm{SO}_{3}$,$\mathrm{OH}$ and $-\mathrm{NH}_{2}$; and $-\mathrm{SO}_{3},-\mathrm{NH}_{2} \mathrm{COOH}$ and a large number of $-\mathrm{OH}$ groups, respectively. ${ }^{19-21}$ These functional groups are bonded to the main chain of the SPF, AS and AH polymers.

The application properties of MA polymer in concrete Effect of MA polymer dosage on water reduction percentage in concrete. Figure 2 shows that the water-reduction percentage values increase with the MA polymer dosage from 0.3 to $0.5 \%$ (the ratio to cement content by mass). Above an MA polymer dosage of $0.5 \%$, the percentage of water reduction increases very slowly. The main reason 
Table 8 FT-IR characteristic bands of the synthesized MA polymer $\left(\mathrm{cm}^{-1}\right)$

\begin{tabular}{llccccccc}
\hline Polymer & $-\mathrm{OH}$ and $-\mathrm{NH}_{2}$ & $-\mathrm{CH}_{2}$ & $-\mathrm{C}=\mathrm{O}$ & $-\mathrm{C}=\mathrm{C}$ & $-\mathrm{C}=\mathrm{N}$ & $-\mathrm{S}=\mathrm{O}$ & $-\mathrm{C}-\mathrm{N}$ & $-\mathrm{C}_{6} \mathrm{H}_{5}$ \\
\hline SPF & $3430.8(-\mathrm{OH})$ & 3000 & - & 1636.5 & - & 1186.5 and 1044.1 & - \\
AS & 3484.76 & 2921.50 & - & 1603 & 1300.53 & 1122.5 and 1033.1 & 1175.3 & 828.56 \\
AH & 3384.54 & 2921.86 & 2718.41 & 1600.87 & 1335.59 & 1124.4 and 1034.27 & 1178.6 & 826.68
\end{tabular}

Abbreviations: AH, aminosulfonate-phenol-salicylic acid-formaldehyde polymer; AS, aminosulfonate-phenol-formaldehyde polymer; FT-IR, Fourier transform infrared; MA, monocyclic aromatic; SPF, sulfonated phenol-formaldehyde polymer.

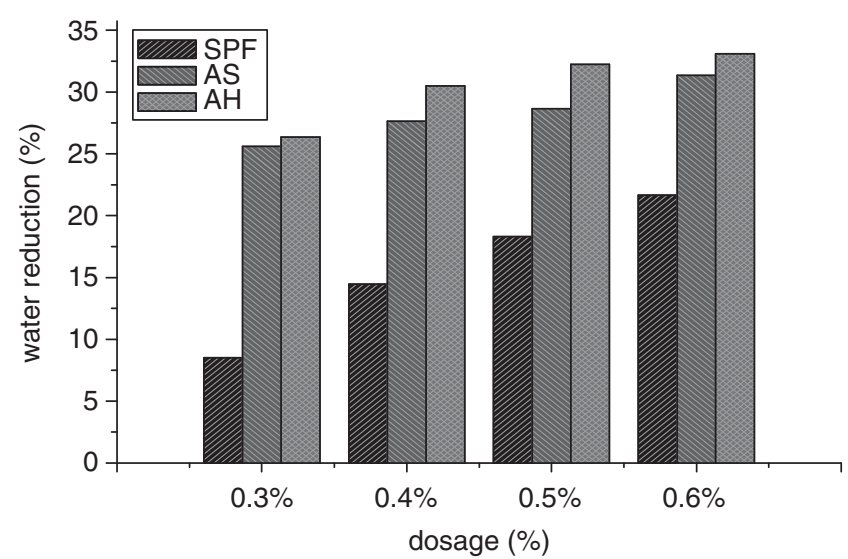

Figure 2 Water-reduction percentage by monocyclic aromatic (MA) polymer at different dosages. A full color version of this figure is available at Polymer Journal online.

for this is that the effect of MA polymer on water reduction in concrete is determined by the degree of adsorption of the polymer on cement particle surfaces and the $\xi$-potential of cement particle surfaces. MA polymer is adsorbed on cement particle surfaces at a monolayer adsorption of $0.3-0.5 \%$, where the dosage and $\xi$-potential of cement particle surfaces are positively related to the polymer dosage. Above a $0.5 \%$ dosage, the cement particle surfaces were fully covered with MA polymer molecules, and with multilayer adsorption, the $\xi$-potential of the cement particle surfaces does not increase with MA polymer dosage. ${ }^{22}$

Figure 2 also indicates that the functional groups bonded to the MA polymers have an effect on the water-reduction percentage. The SPF polymer at $0.5 \%$ dosage showed $18.3 \%$ water reduction, whereas the percentage of water reduction for the AS and $\mathrm{AH}$ polymers at same dosage was $28.5 \%$ and $32.2 \%$, respectively. The $\mathrm{AH}$ polymer exhibited the highest water reduction percentage at the same dosage due to the greater number of $-\mathrm{COOH}$ groups bonded to the $\mathrm{AH}$ polymer.

Effect of MA polymer on workability of concrete. The change in workability of concrete with time slump elapsed is very important for field applications. The lower degree of workability change will prolong the available time for transporting and handling of concrete. ${ }^{23}$ The relationship between the time and workability change of concrete containing MA polymer at different dosages and W/C ratios is shown in Figures 3-5.

From Figure 3, it can be seen that workability of concrete with SPF polymer at different dosages sharply decreases with time elapsed. The main reason for this is that the molecular structure of the SPF polymer has more $-\mathrm{SO}_{3}$ and fewer $-\mathrm{OH}$ groups. The sharp decrease in the workability of the SPF polymer with time elapsed shows that this polymer is not appropriate for in situ applications requiring longer workability times. In Figure 4, the change in workability properties of

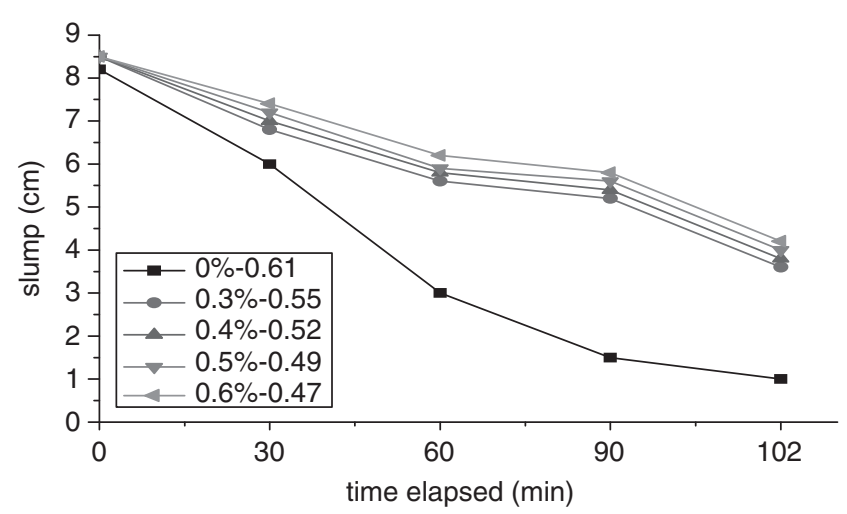

Figure 3 Slump change with time for sulfonated phenol-formaldehyde polymer (SPF) polymer at difference dosages and water/cement (W/C) ratios. A full color version of this figure is available at Polymer Journal online.

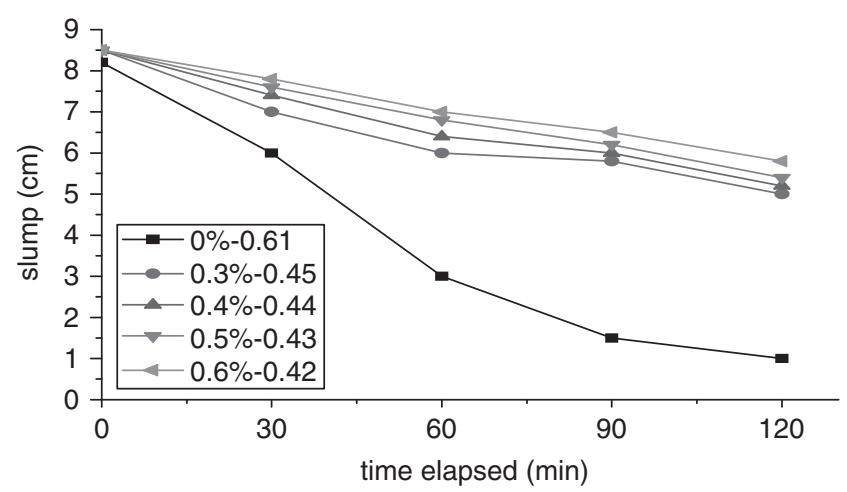

Figure 4 Slump change with time for aminosulfonate-phenol-formaldehyde polymer (AS) polymer at difference dosages and water/cement (W/C) ratios. A full color version of this figure is available at Polymer Journal online.

concretes containing AS polymer with time elapsed at different dosages and $\mathrm{W} / \mathrm{C}$ ratios is presented. Concrete containing AS polymer at different dosages has a better effect on the preservation of fluidity of cement paste; however, the increase in the AS polymer dosage generally decreased the slump loss of concrete with time elapsed.

Figure 5 shows the workability preservation properties of concrete containing $\mathrm{AH}$ polymer at different dosages and $\mathrm{W} / \mathrm{C}$ ratios. The slump loss of concrete containing AH polymer was somewhat smaller than that of concrete containing AS polymer at the same dosage due to the greater number of $-\mathrm{OH}$ and - $\mathrm{COOH}$ functional groups bonded to the $\mathrm{AH}$ polymer molecule.

Effect of MA polymer on setting times of cement pastes. The setting times of cement pastes incorporating a $0.3-0.5 \%$ dosage of MA polymer are presented in Figure 6. The setting times of the investigated 


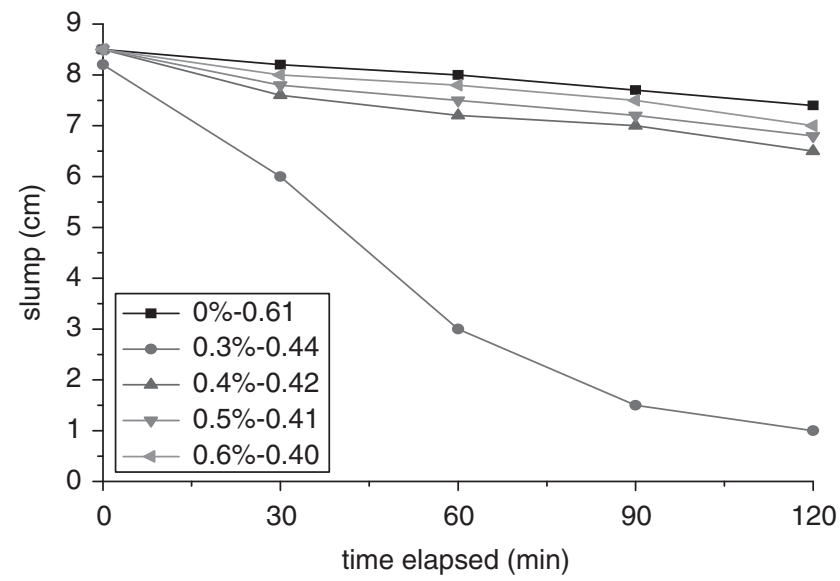

Figure 5 Slump change with time for aminosulfonate-phenol-salicylic acidformaldehyde polymer (AH) polymer at difference dosages and water/cement (W/C) ratios. A full color version of this figure is available at Polymer Journal online.
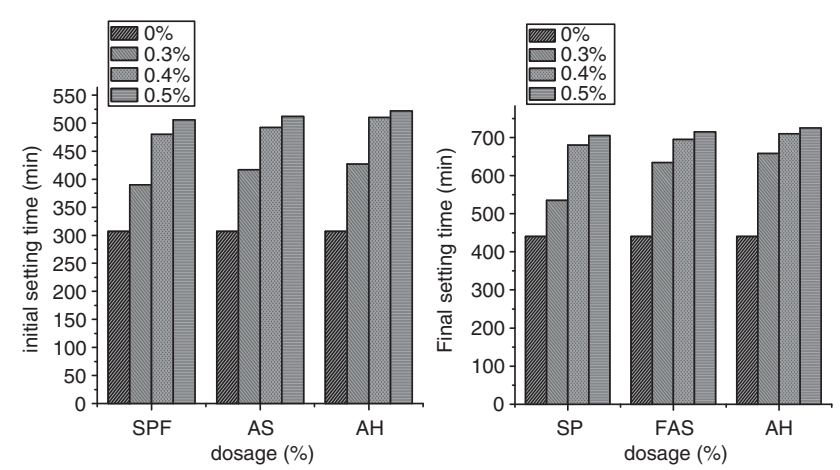

Figure 6 Effect of monocyclic aromatic (MA) polymer on setting times of cement paste. A full color version of this figure is available at Polymer Journal online.

cement pastes were determined using Portland cement with initial and final setting times of 307 and $440 \mathrm{~min}$, respectively.

From Figure 6, it is clear that the MA polymer dosage has an effect on the setting times of cement pastes. The initial and final setting times of cement paste increase rapidly with the addition of MA polymer, from 0 to $0.3 \%$ dosage. The initial setting times of cement pastes containing SPF, AS and $\mathrm{AH}$ polymers at $0.3 \%$ dosage are prolonged by 83,110 and $120 \mathrm{~min}$, respectively, with respect to the initial setting time of cement pastes without polymer. Meanwhile, the final setting times of cement pastes containing SPF, AS and AH polymers are prolonged from a time of $440 \mathrm{~min}$, for cement pastes without polymer, to 535,634 and $658 \mathrm{~min}$, at a $0.3 \%$ polymer dosage. When the dosage of MA polymers is greater than $0.4 \%$, the initial and final setting times increase very slowly for cement pastes containing SPF, AS and AH polymer. The effect of AH polymers on the setting times of the cement pastes at the same dosage is more significant in the three types of MA polymers studied here, which can be related to the type and number of functional groups bonded to the MA polymer molecular structure.

Relationship between setting time and slump loss of concrete. The relationship between the prolonging of the final setting time and slump loss rate of concrete with MA polymer (after $2 \mathrm{~h}$ ) was

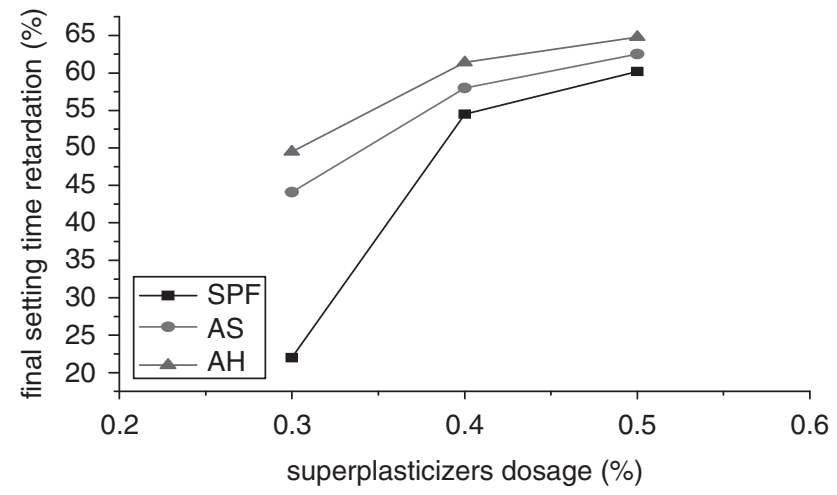

Figure 7 Effects of polymer on lengthening of final setting time at different dosages and water/cement (W/C) ratios. A full color version of this figure is available at Polymer Journal online.

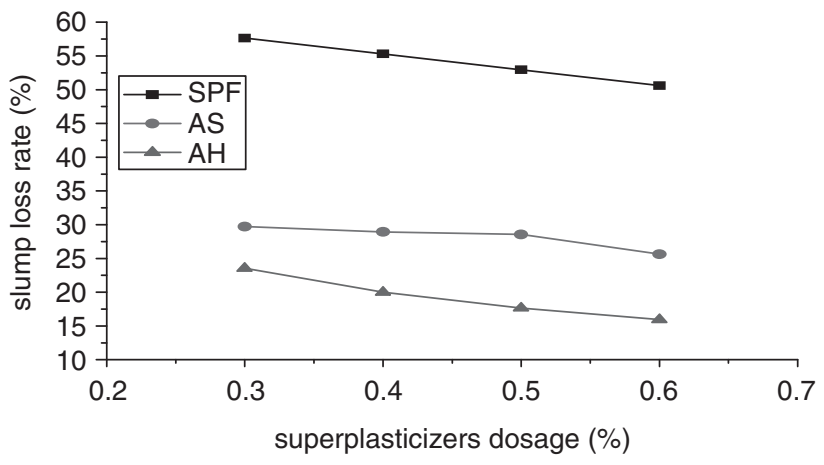

Figure 8 Effects of polymer on slump loss rate (after $2 \mathrm{~h}$ ) at different dosages and water/cement (W/C) ratios. A full color version of this figure is available at Polymer Journal online.

investigated at different dosages and W/C ratios, as shown in Figures 7 and 8.

The properties of MA polymer on the prolonging of the final setting time of cement pastes and slump loss rates of concrete are presented in Figures 7 and 8 . SPF polymer has a smaller negative influence on the prolonging of the final setting time of cement pastes. When using SPF polymer, the slump loss rate of concrete is extremely high and independent of polymer dosage, whereas the final setting time retarding effects of cement pastes containing $\mathrm{AS}$ and $\mathrm{AH}$ polymer are significant at polymer dosages ranging from 0.3 to $0.5 \%$. The slump loss rate of concrete containing AS and $\mathrm{AH}$ polymer is dependent on polymer dosage; proper AS and $\mathrm{AH}$ polymer dosages were used, and it was shown that the slump loss rate of concrete containing AS and AH polymer could be reduced to negligible values.

Studies on the prolonging of the final setting time of cement pastes and the slump loss rate of fresh concrete containing MA polymer at different dosages and W/C ratios show that the application of SPF polymer in concrete with a higher slump loss rate did not lengthen the setting times of cement paste, whereas concrete containing AS and $\mathrm{AH}$ polymer with good workability retention usually prolonged the setting time of cement paste. It is possible to change the application properties of MA polymer in concrete by introducing new functional groups in the main chain of the MA polymer molecule, and it was also proved that concrete with a longer final setting time and a slow slump loss 


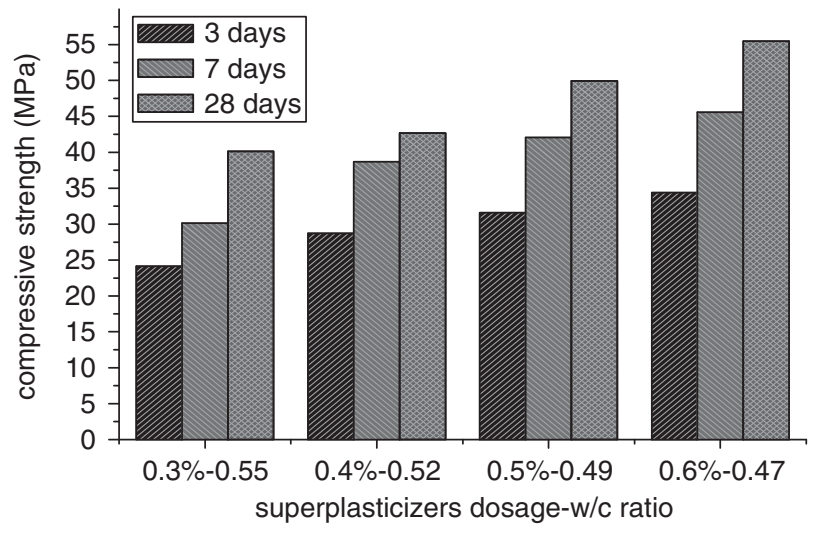

Figure 9 Compressive strength development of sulfonated phenolformaldehyde polymer (SPF) polymer incorporated concretes at different dosages and water/cement (W/C) ratios. A full color version of this figure is available at Polymer Journal online.

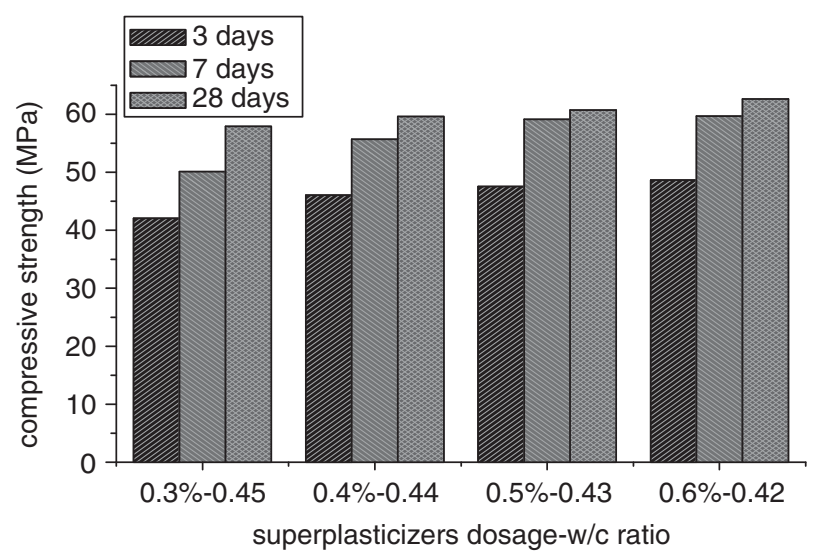

Figure 10 Compressive strength development of aminosulfonate-phenolformaldehyde polymer (AS) polymer incorporated concretes at different dosages and water/cement (W/C) ratios. A full color version of this figure is available at Polymer Journal online.

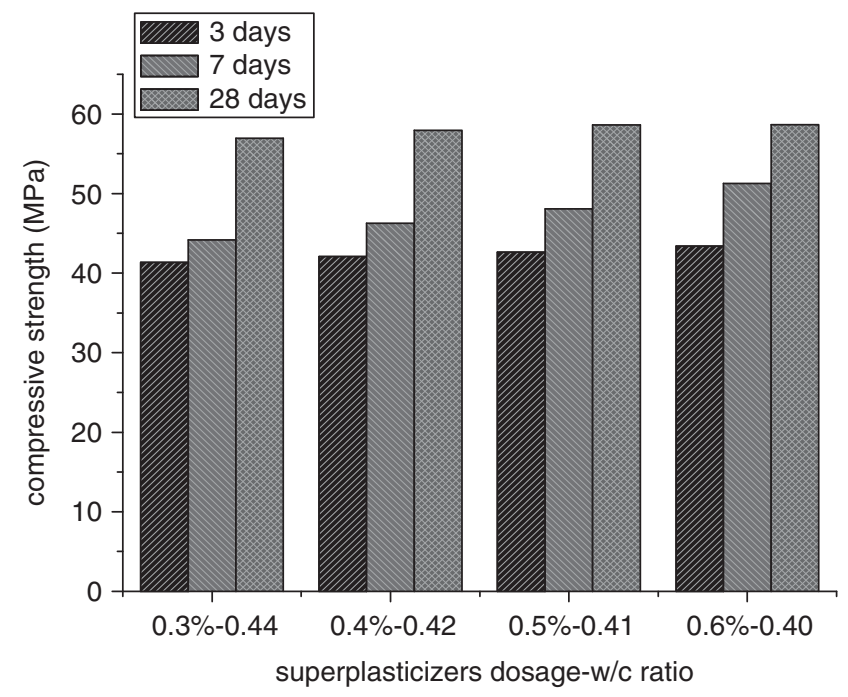

Figure 11 Compressive strength development of aminosulfonate-phenolsalicylic acid-formaldehyde polymer (AH) polymer incorporated concretes at different dosages and W/C ratios. A full color version of this figure is available at Polymer Journal online. rate over a period of $2 \mathrm{~h}$ could be created by using the AS and $\mathrm{AH}$ polymer at appropriate dosages $(0.6 \%)$.

Effect of MA polymer on the compressive strength development of concrete. The most critical influence of the polymers was that on the change in the development of compressive strength in concrete. The development of compressive strength in concrete without polymer was compared with that of concrete with MA polymer at 3, 7 and 28 days, as shown in Figures 9-11.

Figures 9-11 show that the compressive strength of concrete without polymer and with MA polymer at different dosages and W/C ratios increases after curing for 3,7 and 28 days. The early compressive strength development of concrete containing MA polymer is very rapid. The 3-day compressive strength of concrete containing $0.5 \%$ MA polymer reached $70-80 \%$ after curing for 28 days and the 7-day compressive strength of concrete containing $0.5 \%$ MA polymer was $80-95 \%$ after curing for 28 days. The compressive strength of concrete without polymer and with MA polymer at different dosages and W/C ratios increases at later curing ages.

The compressive strength of concrete containing $0.3 \%$ SPF, AS and AH polymer can reach $24.13,30.12$, and $40.13 \mathrm{MPa} ; 42.04,50.12$, and 57.92 MPa and 41.36, 44.18, and 56.97 MPa at curing times of 3, 7 and 28 days, respectively. The compressive strength was 135, 126 and $114 \%$; 235, 211 and 165\%; and 232, 186 and 162\% for concrete without polymer at the same curing time. The compressive strength of concrete containing MA polymer is higher than that of concrete without polymer at the same curing time. The higher compressive strength values of concrete were obtained from concretes containing MA polymer, which are due to the high water-reducing capacity of the MA polymer, which also results in a decrease in the W/C ratio.

The compressive strength of concrete containing MA polymer at the same curing time and dosage shows some differences because of the molecular structures of the different MA polymers. The compressive strength of concrete containing the AS and AH polymers is higher than that of concrete containing the SPF polymer at the same curing time and polymer dosage. Concrete containing the AS polymer has a higher compressive strength than that of concrete containing the $\mathrm{AH}$ polymer at the same dosage because the molecular structure of the $\mathrm{AH}$ polymer features more $-\mathrm{OH}$ and $-\mathrm{COOH}$ groups than that of the AS polymer. As a result, the effect of the AH polymer on the prolonging of the final setting time of cement paste at the same polymer dosage is more significant than that of the AS polymer.

\section{CONCLUSIONS}

On the basis of results of this experimental investigation, the following conclusions are drawn:

1. MA polymer was synthesized. Gel permeation chromatography shows that the MA polymers have approximately the same MW. The Fourier transform infrared spectra show that the molecular structures of the SPF, AS and $\mathrm{AH}$ polymers have $-\mathrm{OH}$ and $-\mathrm{SO}_{3}$; $-\mathrm{SO}_{3},-\mathrm{OH}$ and $-\mathrm{NH}_{2}$; and $-\mathrm{SO}_{3},-\mathrm{NH}_{2}-\mathrm{COOH}$ and a greater number of $-\mathrm{OH}$ groups. These functional groups are chemically bonded to the main chain of the SPF, AS and AH polymer molecules.

2. MA polymer has a higher water-reduction percentage at a lower dosage. An MA polymer dosage greater than $0.5 \%$ produces a very slow increase in the percentage of water reduction. The waterreducing capacity of the MA polymers follows the order $\mathrm{AH}>\mathrm{AS}>\mathrm{SPF}$ at the same polymer dosage. 
3. The workability preservation properties of concrete containing MA polymer with time at the same dosages and $\mathrm{W} / \mathrm{C}$ ratios ranks $\mathrm{AH}>\mathrm{AS}>\mathrm{SPF}$.

4. The setting times of cement paste increase rapidly with the addition of MA polymer from 0 to $0.3 \%$ dosage. At a dosage of MA polymer greater than $0.4 \%$, the setting times of the cement pastes containing MA polymer increase very slowly. The retardation of the setting time for cement pastes featuring the three types of MA polymer follows the order AH $>$ AS $>$ SPF.

5. The molecular structure of the SPF polymer has more $-\mathrm{SO}_{3}$ and less $-\mathrm{OH}$ groups. SPF polymer shows a high percentage of water reduction, high slump loss and poor workability-preservation properties. The molecular structure of the AS and $\mathrm{AH}$ polymers possess $-\mathrm{SO}_{3}$ and $-\mathrm{COOH}$ as dispersion groups and $-\mathrm{OH}$ and $\mathrm{NH}_{2}$ as fluidity-preservation groups. AS and $\mathrm{AH}$ polymers have better water-reducing capacity and workability preservation properties and show prolonged setting times of cement paste and higher compressive strengths in concrete than SPF polymer at the same curing time and same dosage.

\section{ACKNOWLEDGEMENTS}

We acknowledge Jiangsu Bote New Materials Co., Ltd for providing AS superplasticizer. We thank Ming Deng, Professor of Nanjing University of Technology; his sponsorship and support made this study possible.

1 Aitcin, P. C. Cements of yesterday and today concrete of tomorrow. Cement Concr. Res. 30, 1349-1359 (2000).

2 Collepardi, M. \& Valente, M. Recent Developments in Superplasticizers, Eighth CANMET/ACl International Conference. Superplasticizers and other Chemical Admixtures in Concrete 1-14 (American Concrete Institute: USA, 2006).

3 Aitcin, P. C., Jolicoeur, C. \& MacGregor, J. G. Superplasticizers; how they work and why they occasionally don't? Concr. Int. 16, 45-52 (1994).

4 Gagne, R., Boisvert, A. \& Pegeon, M. Effect of superplasticizer dosage on mechanical properties, permeability and freeze-thaw durability of high-strength concrete with and without silica fume. ACl Mater. J. 93, 111-120 (1996).
5 Sakai, E., Ishida, A. \& Ohta, A. New trend in the development of concrete admixtures in Japan. J. Adv. Concr. 4, 211-233 (2006).

6 Paillere, A. M. Application of Admixtures in Concrete 56-68 (E \& FN Spon: London, 1996).

7 Lim, G.- G., Hong, S. S., Kim, D.- S., Lee, B.- J. \& Rho, J.- S. Slump loss control of cement paste by adding polycarboxylic type slump-releasing dispersant. Cement Concr. Res. 29, 223-229 (1999).

8 Papo, A. \& Piani, L. Effect of various superplasticizers on the rheological properties of Portland cement pastes. Cement Concr. Res. 34, 2097-2101 (2004).

9 Felekoglu, B. \& Sarỳkahyaetal, H. Effect of chemical structure of polycarboxylate based superplasticizers on workability retention of self-compacting concrete. Constr. Build Mater 22, 1972-1980 (2008).

10 Chen, S. D., Hwang, C. H. \& Hsu, K. C. The effects of sulphonated phenolic resins on the properties of concrete. Cement Concr. Res. 29, 255-259 (1999).

11 Kung-chung, H. S. U., Sheng-Da, C. \& Nan, S. Water-soluble sulfonated phenolic resins. III. Effects of degree of sulfonation and molecular weight on concrete workability. J. Appl. Polym. Sci. 76, 1762-1766 (2000).

12 Ouyang, X., Jiang, X., Qiu, X. \& Yang, D. Effect of molecular weight of sulfanilic acidphenol-formaldehyde condensate on the properties of cementitious system. Cement Concr. Res. 39, 283-288 (2009).

13 Pei, M., Dujin, W., Xianbo, H. \& Duanfu, X. Synthesis of sodium sulfanilate-phenolformaldehyde condensate and its application as a superplasticizer in concrete. Cement Concr. Res. 30, 1841-1845 (2000).

14 Meishan, P., Zhenfei, W., Wenwei, L., Jin, Z., Qiwei, P. \& Xiaojuan, Q. The properties of cementitious materials superplasticized with two superplasticizers based on aminosulfonate-phenol-formaldehyde. Constr. Build Mater. 22, 2382-2385 (2008).

15 BS EN 197 Part 1. Cement. Composition, specifications and conformity criteria for common cements. British Standards Institution (2000).

16 GOST10180. [Concretes. Methods for strength determination using reference specimens]. Gosudarstvennye Standarty State Standard (Russian): (1990).

17 BS EN 12350 Part 2: testing fresh concrete. Slump test. British Standards Institution (2000).

18 EN 196-3. Methods of testing cement-determination of setting time and soundness. British Standards Institution (1995).

19 Ye, Y.- S., Huang, H.- L. \& Hsu, K.- C. A water-soluble acrylate/sulfonate copolymer. I. Its synthesis and dispersing ability on cement. J. Appl. Polym. Sci. 100, 2490-2496 (2006).

20 Aiad, I. \& Hafiz, A. A. Structural effect of prepared and commercial superplasticizers on performance of cement pastes. J. Appl. Polym. Sci. 90, 482-487 (2003).

21 Rosana, M. N., de Assunc, Royer, B., Oliveira, J. S., Filho, G. R. \& de Castro Motta, L. A. Synthesis, characterization and application of the sodium poly (styrenesulfonate) produced from waste polystyrene cups as an admixture in concrete. J. Appl. Polym. Sci. 96, 1534-1538 (2005).

22 Yoshioka, K., Tazawa, E.-I., Kawai, K. \& Enohata, T. Adsorption characteristics of superplasticizers on cement component minerals. Cement Concr. Res. 32, 1507-1513 (2002).

23 Felekoglu, B. \& Sarlkahya, H. Effect of chemical structure of polycarboxylate based superplasticizers on workability retention of self-compacting concrete. Constr. Build Mater. 5, 1972-1980 (2007). 